\title{
Premature ejaculation patients and their partners: Arriving at a clinical profile for a real optimization of the treatment
}

\author{
Paolo Verze ${ }^{1}$, Roberto La Rocca ${ }^{1}$, Lorenzo Spirito $^{1}$, Gianluigi Califano ${ }^{1}$, Luca Venturino ${ }^{1}$, \\ Luigi Napolitano $^{1}$, Antonio Cardi ${ }^{2}$, Davide Arcaniolo ${ }^{3}$, Claudia Rosati ${ }^{4}$, Alessandro Palmieri ${ }^{1}$, \\ Vincenzo Mirone $^{1}$ \\ ${ }^{1}$ Department of Neurosciences, Reproductive Sciences and Odontostomatology, Urology Section, University of Naples Federico II, Naples, Italy; \\ 2 Department of Urology, San Giovanni Hospital, Rome, Italy; \\ ${ }^{3}$ Department of Urology, Vanvitelli University, Naples, Italy; \\ ${ }^{4}$ Department of Clinical Medicine and Surgery, University of Naples Federico II, Naples, Italy.
}

\section{Summary The aim of the study is to extrapolate clini- cal features of Premature Ejaculation (PE)} patients and female partners of men affected with PE, in order to get a profile that can be of assistance for physicians within the dynamics of a couple, one of which is a PE patient. An observational, non-interventional, cross-sectional epidemiological study entitled IPER (Italian Premature Ejaculation Research) was conducted and included two different cohorts of subjects that were randomly sampled from a patient dataset of selected General Practitioners: 1. IPER-M sub-cohort (1.104 subjects) was made of male subjects in which they were then distinguished patients with or without PE based on the score of the PEDT questionnaire; IPER-F sub-cohort (1.109 subjects) was made of female subjects from an independent sample of women (therefore not the partners of the IPER-M males) in which they then distinguished those partners of a male subject with PE or not. In addition to an identical general questionnaire to explore demographic aspects and habits, each subcohort was then evaluated using validated questionnaires. No differences were noted between PE+/PE- patients in terms of alcohol consumption, smoking habits, physical activity nor stress condition in everyday life, employment, socio-economic class and marital status.

While the prevalence of $\mathrm{PE}$ proportionally increased with age, excluding the 50-59 and 70-80 years decades, in the IPER-M group an overall statistically significant difference for the mean age between the PE+ and PE- groups $(p=0.002)$ was detected, but without reaching any difference amongst the different age classes in the IPER-F group. The PE+ patients reported a significantly lower frequency rate of sexual intercourse, worse $2 o L$ ( $p=0.006$ and $p<0.0001$, respectively), and increased anxiety status ( $p<0.0001$ for both subgroups). This study shows that, rather than talking with a patient affected by PE it would be advisable to introduce the concept of couple counseling with the person patient and his partner, because it is only through classification of both partners as one couple and a full understanding of their mutual sexual experience that PE treatment can be optimized and its results measured accurately.

KEY WORDS: Premature ejaculation; Partner; Profile; Clinical. Submitted 4 May 2020; Accepted 15 May 2020

\section{INTRODUCTION}

Premature Ejaculation (PE) is the most frequent male sexual disorder but, despite its high frequency, as a medical disorder it is poorly understood. Patients are often unwilling to discuss their symptoms and many physicians are not educated enough on effective treatments. As a result, patients may be misdiagnosed or mistreated (1).

The ISSM Committee defines lifelong PE as an ejaculation that always or nearly always occurs prior to, or within about 1 minute of, vaginal penetration from the first sexual encounter, together with the inability to retard ejaculation during vaginal penetration which results in negative personal consequences such as distress, bother, frustration, and/or the avoidance of sexual intimacy (2). Based upon this definition, timing, a feeling of loss-ofcontrol and, couple distress are the main aspects to be taken into account when facing a patient with PE.

In fact, PE has been associated with significant bother, interpersonal problems and dissatisfaction with sexual intercourse for both males and their partners (3-5). Therefore patient's and their partner's satisfaction play a crucial role in a PE diagnosis and physiopathology more than in other sexual dysfunction (6) and PE could even be categorized as a partner-oriented and indeed partnergenerated male sexual dysfunction, because the symptoms are strictly related to partner's sexual physiology and to the female sexual response (7). Furthermore, data from previous studies show that all female sexual domains (including desire, arousal, lubrication, orgasm) become significantly impaired when partners of men affected with PE $(8,9)$.

Despite some efforts to understand in detail the clinical characteristics of PE patients and their partners, to date it has proven difficult to provide a definitive clinical profile of a PE patient and the impact on their partner.

The absence of this clinical information makes the profiling and management of the couple more complex.

The primary objective of this study was to extrapolate the clinical features of PE patients and their partners in order to arrive at a profile that can be of assistance to physicians in treating couples, one of whom is an PE patient. 


\section{Patients And methods}

An observational, non-interventional, cross-sectional epidemiological study Italian Premature Ejaculation Research (IPER) was conducted on a cohort of adult males (IPER-M) and females (IPER-F) that were randomly sampled from a patient dataset of selected General Practitioners (GPs) throughout Italy, applying the same methodology for both cohorts. Main criteria for patient enrollment and study design have been previously described $(10,11)$.

The inclusion criteria were adult men and women between the ages of 18 and 80 , sexually active of any ethnicity, even if the subjects were predominantly Italian. Those who were unable to fill in questionnaires due to cognitive or linguistic problems or with a clear indication of no sexual activity at the time of questionnaire administration were excluded. All participants, after signing an informed consent form, received a series of questionnaires to be returned anonymously to their GPs in a sealed envelope that was then opened by an independent staff responsible for processing the data.

A general questionnaire was administered for both IPER$\mathrm{M}$ and IPER-F cohorts. The IPER-M study population was asked to complete in the following validated selfadministered questionnaires: Premature Ejaculation Diagnostic Tool (PEDT), International Index of Erectile Function (IIEF-5), Sexual Quality of Life QuestionnaireMale) (SQoL-M), Self-rating Depression Scale (SDS) and Self-rating Anxiety Scale (SAS).

The female patients from the IPER-F study cohort were asked to report on their partner's ejaculation time (selfreported Intravaginal ejaculation latency time - IELT) and presence of sexual dysfunction (including no interest in sex, lack of or delayed orgasm, pain during ejaculation, anxiety and lubrication problems). Patients were also asked to complete the following validated questionnaires: adapted from Female Sexual Distress Scale (FSDS-R-PE), Sexual Quality of Life Questionnaire-Female (SQoL-F), SDS and SAS. The study did not involve any treatment or invasive diagnostic procedure. Per Italian law the survey was conducted in accordance with the Privacy Act and with the Declaration of Helsinki in all aspects which were applicable. Each subject was informed about the purpose of the investigation and was recruited after signing an informed consent form.

\section{Statistics}

A descriptive statistical analysis was applied to present results. When appropriate, intra-group comparisons were performed by $\chi^{2}$ tests for categorical variables or by variance analysis (ANOVA) for continuous variables.

Multiple logistic regression models were used to identify independent risk factors for PE.

The statistical significance level (p) was 0.05 or less or all statistical tests. Data were normally distributed in line with an asymmetry and kurtosis analysis.

Data were analyzed using SAS software, version 9.2 (SAS Institute Inc., Cary, NC, USA).

\section{RESULTS}

For the IPER-M sub-cohort a total of 2.571 male patients were sampled and 1.104 (43\%) were recruited into the study. For the IPER-F sub-cohort 3.104 female subjects were sampled and, of those, 1.109 were included in the study.

Table 1 describes demographics and general characteristics of both IPER-M and IPER-F sample cohorts. The mean age of the IPER-M sample was 45.6 years \pm 16.9 , with $39.6 \%$ of the sample aged less than 45 years old. The mean age of the IPER-F cohort was 45.1 years \pm 15.4 $\mathrm{SD}$, with $44 \%$ of the sample aged less than 45 years old. No differences were noted between the PE+/PE- patients in both IPER-M and IPER-F sub-cohorts in terms of alcohol consumption?, smoking habits, physical activity or stress conditions in everyday life as well as employment status, socio-economic class and marital status.

Instead a greater amount of $\mathrm{PE}+$ patients with a lower

\section{Table 1.}

Demographics and general characteristics of the study population. A: Iper-M Sub-cohort

\begin{tabular}{|c|c|c|c|}
\hline & $\mathrm{PE}+\mathrm{Group}(\mathrm{n}=119)$ & PE- Group ( $n=990$ ) & \\
\hline \multicolumn{4}{|c|}{ ( } \\
\hline \multicolumn{4}{|l|}{ Median (SD) - $45.6( \pm 16.9)$} \\
\hline Body Mass Index $\left(\mathrm{kg} / \mathrm{cm}^{\wedge}\right)^{\prime}$ & & & $p<0.6522$ \\
\hline Median (SD) & $25.58(3.72)$ & $25.74(4.81)$ & \\
\hline Smoking habits (cig./day) & & & $p=0.5588$ \\
\hline Never (n. \%) & $293(41.50 \%)$ & $62(38.50 \%)$ & \\
\hline$<10($ n. \%)) & $108(15.29 \%)$ & $20(12.42 \%)$ & \\
\hline$>10(\mathrm{n} . \%)$ & $136(19.26 \%)$ & $36(22.36 \%)$ & \\
\hline ex smoker (n. \%) & $169(23.93 \%)$ & $43(26.70 \%)$ & \\
\hline Alcohol consumption & & & $p=0.1428$ \\
\hline Never (n. \%) & $139(19.85 \%)$ & $22(13.75 \%)$ & \\
\hline Occasional (n. \%) & $437(62.42 \%)$ & $103(64.37 \%)$ & \\
\hline Regular (n. \%) & $124(17.71 \%)$ & $35(21.87 \%)$ & \\
\hline Physical activity & & & $p=0.2073$ \\
\hline Never (n. \%) & $248(35.42 \%)$ & $68(43.03 \%)$ & \\
\hline Low (n. \%) & $152(21.71 \%)$ & $30(18.98 \%)$ & \\
\hline Moderate (n. \%) & $223(31.85 \%)$ & $49(31.01 \%)$ & \\
\hline Intense (n. \%) & 77 (11.00\%) & $11(6.96 \%)$ & \\
\hline Stress condition (everyday life) & & & $p=0.3307$ \\
\hline $\operatorname{Never}(\mathrm{n} . \%)$ & $44(6.24 \%)$ & $9(5.59 \%)$ & \\
\hline Low (n. \%) & $279(39.57 \%)$ & $52(32.29 \%)$ & \\
\hline Moderate (n. \%) & $314(44.53 \%)$ & $83(51.55 \%)$ & \\
\hline Intense (n. \%) & $68(9.64 \%)$ & $17(10.55 \%)$ & \\
\hline Marital status & & & $p=0.0978$ \\
\hline Never married (n. \%) & $257(36.35 \%)$ & $42(26.25 \%)$ & \\
\hline Married (n. \%) & $398(56.29 \%)$ & $102(63.75 \%)$ & \\
\hline Divorced (n. \%) & $43(6.08 \%)$ & $13(8.12 \%)$ & \\
\hline Widower (n. \%) & $9(1.27 \%)$ & $3(1.87 \%)$ & \\
\hline Kind of cohabitation & & & $p=0.0443$ \\
\hline No stable partner (n. \%) & $147(21.64 \%)$ & $33(21.29 \%)$ & \\
\hline No cohabitation (n. \%) & $145(21.35 \%)$ & $20(12.90 \%)$ & \\
\hline stable cohabitation (n. \%) & $102(65.80 \%)$ & $102(65.80 \%)$ & \\
\hline Education & & & $p=0.5670$ \\
\hline No education (n. \%) & $1(0.14 \%)$ & & \\
\hline Primary (n. \%) & $43(6.09 \%)$ & $12(7.50 \%)$ & \\
\hline Secondary (n. \%) & $178(25.21 \%)$ & $47(29.37 \%)$ & \\
\hline High (n. \%) & 367 (51.98\%) & $72(45.00 \%)$ & \\
\hline Degree (n. \%) & $117(16.57 \%)$ & $29(18.12 \%)$ & \\
\hline Economic condition & & & $p=0.3177$ \\
\hline Insufficient (n. \%) & $64(9.10 \%)$ & $11(6.91 \%)$ & \\
\hline Quite insufficient (n. \%) & $180(25.60 \%)$ & $41(25.78 \%)$ & \\
\hline Sufficient (n. \%) & $432(61.45 \%)$ & $96(60.37 \%)$ & \\
\hline Good (n. \%) & 27 (3.84\%) & 11 (6.91\%) & \\
\hline
\end{tabular}




\section{B: Iper-F Sub-cohort}

\begin{tabular}{|c|c|c|c|}
\hline & $\mathrm{PE}+$ Group $(n=119)$ & PE- Group ( $n=990$ ) & \\
\hline Age & & & $p=0.002$ \\
\hline Overall - 45.1 ( \pm 15.4$)$ & & & \\
\hline Median (SD) & $48.6( \pm 14.9)$ & $45.1( \pm 14.1)$ & \\
\hline Body Mass Index $\left(\mathrm{kg} / \mathrm{cm}^{2}\right)$ & & & $p<0.0001$ \\
\hline Median (SD) & $25.3( \pm 4.17)$ & $23.37( \pm 3.99)$ & \\
\hline Smoking habits (cig./day) & & & $p=0.0881$ \\
\hline $\operatorname{Never}(n . \%)$ & $79(66.66 \%)$ & $543(54.86 \%)$ & \\
\hline$<10(n . \%)$ & $15(12.61 \%)$ & $136(13.68 \%)$ & \\
\hline$>1(n . \%)$ & $12(9.90 \%)$ & $129(13.00 \%)$ & \\
\hline Ex smoker (n. \%) & $13(10.81 \%)$ & $182(18.43 \%)$ & \\
\hline Alcohol consumption & & & $p=0.1185$ \\
\hline $\operatorname{Never}(n . \%)$ & $62(52.29 \%)$ & $460(46.48 \%)$ & \\
\hline Occasional (n. \%) & $46(38.53 \%)$ & $473(47.73 \%)$ & \\
\hline Regular (n. \%) & $11(9.17 \%)$ & $57(5.78 \%)$ & \\
\hline Physical activity & & & $p=0.4138$ \\
\hline Never (n. \%) & $71(60.00 \%)$ & 515 (51.99\%) & \\
\hline Low (n. \%) & $17(14.54 \%)$ & $151(15.24 \%)$ & \\
\hline Moderate (n. \%) & $27(21.81 \%)$ & 47 (4.89\%) & \\
\hline Intense (n. \%) & $4(3.63 \%)$ & $277(27.87 \%)$ & \\
\hline Stress condition (everyday life) & & & $p=0.9916$ \\
\hline Never (n. \%) & $5(4.50 \%)$ & $40(4.07 \%)$ & \\
\hline Low (n. \%) & $37(31.53 \%)$ & $312(31.37 \%)$ & \\
\hline Moderate (n. \%) & $62(51.35 \%)$ & 519 (52.54\%) & \\
\hline Intense (n. \%) & $15(12.61 \%)$ & $119(12.00 \%)$ & \\
\hline Marital status & & & $p=0.2348$ \\
\hline never married (n. \%) & $19(16.51 \%)$ & $209(21.10 \%)$ & \\
\hline Married (n. \%) & $92(76.14 \%)$ & $671(67.83 \%)$ & \\
\hline Divorced (n. \%) & $4(3.66 \%)$ & $77(7.78 \%)$ & \\
\hline Widower (n. \%) & $4(3.66 \%)$ & $33(3.27 \%)$ & \\
\hline Kind of cohabitation & & & $p=0.0651$ \\
\hline no stable partner (n. \%) & 17 (14.28\%) & $76(7.72 \%)$ & \\
\hline no cohabitation (n. \%) & $19(16.32 \%)$ & $208(20.98 \%)$ & \\
\hline stable cohabitation (n. \%) & $83(69.38 \%)$ & $706(71.29 \%)$ & \\
\hline Education & & & $p<0.0001$ \\
\hline no education (n. \%) & 0 & $3(0.33 \%)$ & \\
\hline Primary (n. \%) & $26(21.81 \%)$ & $55(5.63 \%)$ & \\
\hline Secondary (n. \%) & $27(22.72 \%)$ & $199(19.95 \%)$ & \\
\hline High (n. \%) & $45(38.18 \%)$ & $526(52.87 \%)$ & \\
\hline Degree (n. \%) & $21(17.27 \%)$ & $207(21.19 \%)$ & \\
\hline Economic condition & & & $p=0.9355$ \\
\hline Insufficient (n. \%) & $10(8.25 \%)$ & $73(7.37 \%)$ & \\
\hline quite insufficient (n. \%) & $29(24.77 \%)$ & $265(26.78 \%)$ & \\
\hline Sufficient (n. \%) & $77(64.22 \%)$ & $619(62.42 \%)$ & \\
\hline Good (n. \%) & $3(2.75 \%)$ & $33(3.40 \%)$ & \\
\hline
\end{tabular}

BMI (22-25) (median 24.87) and PE- subjects with a higher BMI (26-30) (median 25.06) were included in the IPER-M, though without reaching a statistically significant difference. On the contrary, a higher BMI (PE+ 25.3 \pm 4.17 vs PE- $23.37 \pm 3.99 ; \mathrm{p}<0.0001$ ) was recorded in the IPER-F PE+ sub-cohort. Furthermore, a general lower educational level $(\mathrm{p}<0.0001)$ was reported in the $\mathrm{PE}+$ group of the IPER-F sub-cohort, while no differences were observed in this parameter in patients with or without PE in the IPER-M group.

Table 2 reports the PE prevalence stratification data based on age class in the IPER-M and IPER-F subcohorts, according to the self-estimated IELT $(<1$ minute). It is important to underline that within the IPER-M group, with the exception of 50-59 years and 70-80 years, the prevalence of PE proportionally
Table 2.

PE Prevalence according to self-estimated IELT ( $<1$ minute) within IPER-M (A) and IPER-F (B) study populations.

\section{A: Iper-M Sub-cohort}

\begin{tabular}{|lcc|}
\hline & PE+ & PE- \\
\hline$N$ & 139 & 641 \\
Mean age (SD) & $47.9(15.1)$ & $43.2(16.2)$ \\
$<20(\%)$ & $1(1 \%)$ & $9(1.4 \%)$ \\
$21-29(\%)$ & $13(9.5 \%)$ & $98(15.3 \% \%)$ \\
$30-39(\%)$ & $17(11.9 \%)$ & $120(18.7 \%)$ \\
$40-49(\%)$ & $31(22.4 \%)$ & $126(19.7 \%)$ \\
$50-59(\%)$ & $32(22.9 \%)$ & $144(22.4 \%)$ \\
$>=60(\%)$ & $45(32.4 \%)$ & $144(22.4 \%)$ \\
\hline
\end{tabular}

\section{B: Iper-F Sub-cohort}

\begin{tabular}{|lcc|}
\hline & PE+ & PE- \\
\hline$N$ & 90 & 789 \\
Mean age (SD) & $48.6(14.9)$ & $43.7(14.1)$ \\
$<20(\%)$ & 0 & $7(0.8 \%)$ \\
$21-29(\%)$ & $5(5.9 \%)$ & $91(11.5 \%)$ \\
$30-39(\%)$ & $13(14.8 \%)$ & $170(21.6 \%)$ \\
$40-49(\%)$ & $22(24.4 \%)$ & $210(26.7 \%)$ \\
$50-59(\%)$ & $25(28.1 \%)$ & $174(22.1 \%)$ \\
$>=60(\%)$ & $24(26.7 \%)$ & $137(17.3 \%)$ \\
\end{tabular}

increased with age. For each age class, the PEDT score and the self-estimated IELT by the patients showed a similar epidemiological trend increasing with age when the cut-off value for PE diagnosis was considered $<1$ minute. It is worth highlighting that the same data is confirmed when women from the IPER-F sub-cohort reported the age of their PE partner.

On the contrary, within the IPER-F group, an overall statistically significant difference for the mean age between the PE+ and Pe-groups $(48.6 \pm 14.9$ yrs and $45.1 \pm 14.1$ yrs, respectively; $\mathrm{p}=0.002$ ) was detected, but without resulting in any differences amongst the different age classes.

Table 3 reports data on sexual attitudes in both the IPER$\mathrm{M}$ and IPER-F sub-cohorts. It is interesting to note that $\mathrm{PE}+$ patients from the IPER-M sub-cohort reported a significantly lower frequency rate of sexual intercourse than the PE- population and similar findings were also observed in the IPER-F group. Moreover, it was also revealed that PE+ categories in both IPER-M and IPER-F cohorts expressed a more frequent lack of sexual interest, lack of orgasm and pain during intercourse, based upon the questionnaire's response of "Often" and "Always", when compared with the PE- population.

Table 4 reports data concerning overall quality of sexual life as evaluated by the SQoL questionnaire. The IPER-M sub-cohort showed a significantly worse QoL in PE+ subjects when compared to PE- patients (68.27 PE+ vs 89.90 PE-; $p=0.006$, respectively). Similar findings were recorded for the PE+ category of IPER-F group (74.88 PE+ vs 86.13 PE-; $\mathrm{p}<0.0001$, respectively).

Results reported in anxiety and depression scales in both sub-cohorts are presented in Table 5 Interestingly, within both the IPER-M and IPER-F cohorts, the PE+ categories presented a statistically significant higher score in the Z-SAS questionnaire with regards to anxiety status 
Table 3.

Sexual attitudes according to PE status.

A: Iper-M Sub-cohort

\begin{tabular}{|lccc|}
\hline IPER-M & PE+ & PE- & \\
\hline Frequency of intercourse & $\mathrm{N}(\%)$ & $\mathrm{N}(\%)$ & $\mathrm{P}<0.001$ \\
No sexual intercourse & $64(18.4 \%)$ & $102(11.5 \%)$ & \\
Less than once per month & $57(16.4 \%)$ & $116(13.1 \%)$ & \\
2 to 3 times per month & $111(31.9 \%)$ & $256(28.9 \%)$ & \\
Once per week or more & $116(33.3 \%)$ & $412(46.5 \%)$ & \\
\hline Pain during intercourse & $\mathrm{N}(\%)$ & $\mathrm{N}(\%)$ & $\mathrm{P}=0.021$ \\
Never & $205(82.0 \%)$ & $660(88.6 \%)$ & \\
Sometimes & $38(15.2 \%)$ & $76(10.2 \%)$ & \\
Often & $6(2.4 \%)$ & $9(1.2 \%)$ & \\
Always & $1(0.4 \%)$ & $0(0.0 \%)$ & \\
\hline Lack of orgasm & $\mathrm{N}(\%)$ & $\mathrm{N}(\%)$ & $\mathrm{P}=0.006$ \\
Never & $211(81.5 \%)$ & $631(83.2 \%)$ & \\
Sometimes & $27(10.4 \%)$ & $103(13.6 \%)$ & \\
Often & $15(5.8 \%)$ & $16(2.1 \%)$ & \\
Always & $6(2.3 \%)$ & $8(1.1 \%)$ & \\
\hline No interest for sex & $\mathrm{N}(\%)$ & $\mathrm{N}(\%)$ & $\mathrm{P}=0.001$ \\
Never & $197(62.7 \%)$ & $592(71.2 \%)$ & \\
Sometimes & $78(24.8 \%)$ & $193(23.2 \%)$ & \\
Often & $24(7.6 \%)$ & $27(3.2 \%)$ & \\
Always & $15(4.8 \%)$ & $19(2.3 \%)$ & \\
& & & \\
\hline
\end{tabular}

\section{B: Iper-F Sub-cohort}

\begin{tabular}{|lccc|}
\hline IPER-M & PE+ & PE- & \\
\hline Frequency of intercourse & $\mathrm{N}(\%)$ & $\mathrm{N}(\%)$ & $\mathrm{p}<0.001$ \\
No sexual intercourse & $16(15.5 \%)$ & $94(13,2 \%)$ & \\
Less than once per month & $14(12.4 \%)$ & $101(10.9 \%)$ & \\
2 to 3 times per month & $33(34.9 \%)$ & $220(25.9 \%)$ & \\
Once per week or more & $31(33.3 \%)$ & $372(48.5 \%)$ & \\
\hline Pain during intercourse & $\mathrm{N}(\%)$ & $\mathrm{N}(\%)$ & $\mathrm{p}=0.0247$ \\
Never & $71(79.6 \%)$ & $659(84.2 \%)$ & \\
Sometimes & $17(17.8 \%)$ & $87(11.2 \%)$ & \\
Often & $6(2.4 \%)$ & $26(4.6 \%)$ & \\
Always & $1(0.0 \%)$ & $0(0.0 \%)$ & \\
\hline Lack of orgasm & $\mathrm{N}(\%)$ & $\mathrm{N}(\%)$ & $\mathrm{p}=0.009$ \\
Never & $75(82.4 \%)$ & $660(85.1 \%)$ & \\
Sometimes & $10(11.6 \%)$ & $105(12 \%)$ & \\
Often & $3(3.7 \%)$ & $15(1.8 \%)$ & \\
Always & $2(2.3 \%)$ & $8(1.1 \%)$ & \\
\hline No interest for sex & $\mathrm{N}(\%)$ & $\mathrm{N}(\%)$ & $\mathrm{p}=0.001$ \\
Never & $52(61.3 \%)$ & $618(72.6 \%)$ & \\
Sometimes & $21(24.3 \%)$ & $212(25.4 \%)$ & \\
Often & $8(9.5 \%)$ & $12(1.2 \%)$ & \\
Always & $3(3.9 \%)$ & $10(0.8 \%)$ & \\
& & & \\
\hline
\end{tabular}

Table 4.

Mean Scores at SQoL Questionnaires

A: Iper-M Sub-cohort

\begin{tabular}{|lclclc|}
\hline IAll subjects & \multicolumn{3}{l}{ PE+ subjects } & \multicolumn{2}{l|}{ PE- subjects } \\
\hline$n$ & 950 & $\mathrm{~N}$ & 150 & $\mathrm{~N}$ & 664 \\
Mean & 85,32 & Mean & 68,27 & Mean & 89,90 \\
St.Dev & 20,09 & St.Dev & 22,66 & St.Dev & 16,16 \\
\hline
\end{tabular}

\section{B: Iper-F Sub-cohort}

\begin{tabular}{|lclclc|}
\hline All subjects & \multicolumn{3}{l}{ PE+ partner } & \multicolumn{3}{l|}{ PE- partner } \\
\hline $\mathrm{n}$ & 992 & $\mathrm{~N}$ & 95 & $\mathrm{~N}$ & 897 \\
Mean & 85,05 & Mean & 74,88 & Mean & 86,13 \\
St.Dev & 16,42 & St.Dev & 19,15 & St.Dev & 15,73 \\
Median & 91,7 & Median & 79,6 & Median & 92,6 \\
& & & & & \\
\end{tabular}

Table 5.

Anxiety and depression profile according to ZSAS and ZSDS questionnaires.

\section{A: Iper-M Sub-cohort}

\begin{tabular}{|lccc|}
\hline & PE+ Group & PE- Group & \\
\hline Anxiety (Z-SAS questionnaire) & & & $p<0.0001$ \\
Normal - Total score $<45($ (n. \%) & $123(87.2 \%)$ & $603(95 \%)$ & \\
Mild - Total score 45-59 (n. \%) & $15(10.6 \%)$ & $31(4.9 \%)$ & \\
Moderate - Total score 60-74 (n. \%) & $3(2.1 \%)$ & $1(0.2 \%)$ & \\
\hline Depression (Z-SDS questionnaire) & & & $p=0.5237$ \\
Normal - Total score $<45$ (n. \%) & $131(91.0 \%)$ & $620(95.5 \%)$ & \\
Mild - Total score 45-59 (n. \%) & $9(6.3 \%)$ & $28(4.3 \%)$ & \\
Moderate - Total score 60-69 (n. \%) & $4(2.8 \%)$ & $1(0.2 \%)$ & \\
& & & \\
\hline
\end{tabular}

\section{B: Iper-F Sub-cohort}

\begin{tabular}{|lccc|}
\hline & PE+ Group ( $\mathbf{n}=$ 119)PE- Group ( $\mathbf{n}=\mathbf{9 9 0}$ ) \\
\hline Anxiety (Z-SAS questionnaire) & & & $\mathrm{p}<0.0001$ \\
Normal - Total score $<45(\mathrm{n} . \%)$ & $82(69.04 \%)$ & $838(84.65 \%)$ & \\
Mild - Total score 45-59 (n. \%) & $32(27.38 \%)$ & $140(14.15 \%)$ & \\
Moderate - Total score 60-74 (n. \%) & $5(3.57 \%)$ & $12(1.19 \%)$ & \\
\hline Depression (2-SDS questionnaire) & & & $p=0.4967$ \\
Normal - Total score < 45 (n. \%) & $106(88.75 \%)$ & $896(90.43 \%)$ & \\
Mild - Total score 45-59 (n. \%) & $10(8.75 \%)$ & $84(8.54 \%)$ & \\
Moderate - Total score 60-69 (n. \%) & $3(2.50 \%)$ & $10(1.02 \%)$ & \\
& & &
\end{tabular}

(Z-SAS score > 45) compared to the PE- group (IPER-M: 12.7 PE+ \% vs 5,1 PE-, p < 0.0001; IPER-F: $30.95 \%$ vs $15.34 \%$, respectively; $\mathrm{p}<0.0001)$. On the contrary, with regards to depression status (Z-SDS score $>50$ ), no statistically significant difference between the PE+ and PEgroups in both IPER-M and IPER-F sub-cohorts was revealed $(p=0.5237$ IPER-M and $p=0.4967$ IPER-F, respectively).

\section{Discussion}

Data from this large observational, non-interventional, cross-sectional, epidemiological study help us to get clinical profiles of patients affected by PE and its impact on their partner, providing important details to treat the couple as a whole in an optimal way.

As far as we know, this study has some peculiarities in the selection methodology of the samples that distinguish it from many previous publications. In particular, the sample extraction method guarantees an excellent representation of the real population of patients affected by this disorder. Secondly, the female sample of this study is not made up, as in previous publications, of the partners of the male patients analyzed, but rather by an independent sampling of women who reported having a partner with premature ejaculation. This distinction has allowed us to validate certain data (prevalence data, sexual attitudes, etc.) on two cohorts of totally independent subjects.

Finally, the major strength of this study is that sexuality and neuro-psychic comorbidities have been evaluated by using validated questionnaires which provided a very precise general and sexual profile of the sample.

Overall, what analysis of the data tells us is that in couples where one patient suffers from PE there is a significant problem of sexual dissatisfaction, which is accom- 
panied by a progressive reduction in the frequency of sexual contact as well as the onset of a state of anxiety for both partners.

From a general point of view, neither the patient nor the partners in the study present a personal profile or lifestyle that highlights risk factors which correlate with the presence of PE. Our study confirms data already reported in the literature, whereby PE is not affected by marital or income status (12). On the contrary, with regards to data concerning lifestyle, some of our data conflicts with previously published studies (13). In particular, in our series, obesity does not seem to characterize the PE patient, including, as well as, lack of physical activity, alcohol consumption and smoking status. Instead, a certain correlation with psychological factors such as emotional problems and stress is confirmed $(14,15)$.

What is, instead, very important to highlight from an epidemiological point of view, is that our series reveal, contrary to conclusions in the literature, that there is a certain linear correlation between the prevalence of PE and age, which is confirmed by the two independent samples of the IPER-M and IPER-F sub-cohorts. We are aware of the novelty of this data, although it was already presented in a recent publication (10) of the PEPA survey, to date the most representative epidemiological study, which reported increased PE prevalence with age up to 45-50 years. However beyond this age range no further increase was reported and this result could be explained by the fact that the PEPA study had been conducted as an internet survey and perhaps 45-80 years old subjects were not fully representative of the general population (16).

Data from previous studies show that both men with PE and their partners are more likely to report low satisfaction with their sexual relationship, low satisfaction with sexual intercourse, difficulty relaxing during intercourse, and less frequent intercourse $(3,17)$.

This data is largely confirmed by our study in which first of all, there was a strong reduction in the interest in sexual activity in both the PE patients and partners, as demonstrated by the low weekly frequency of sexual relations.

Once again the relevance of the data is strengthened by the fact that an identical trend comes from two subcohorts of completely independent subjects, who are not partners in a couple. As clearly demonstrated by the data concerning the sexual attitudes of study populations and by the results of the SQoL questionnaire, a couple in which there is a male subject affected by PE has a strongly altered sex life from a qualitative point of view in that there is a high risk of not achieving orgasm for both partners.

This data, in our opinion, obviously closely correlates and explains the reduction in the frequency of sexual intercourse found in both sub-cohorts IPER-M and IPER-F in our study, since it is easy to imagine that a couple who does not have a satisfying sex life tends to reduce the frequency of intercourses. This finding contrasts with data from other Authors who showed that sex drive and overall interest in sex do not appear to be affected by PE (18).

In our view, what remains extremely difficult to explain is how it is possible that a couple that has a similar difficulty in a sexual relationship and above all a reduced quality of the same, tends not to seek help to solve the problem. In the Global Study of Sexual Attitudes and Behaviors survey, $78 \%$ of men who self-reported a sexual dysfunction sought no professional help or advice for their sexual problems, with men more likely to seek treatment for ED than for PE (19). Similarly, in the Premature Ejaculation Prevalence and Attitudes survey, only 9\% of men with self-reported PE consulted a doctor (20).

However, the negative impact of PE extends beyond sexual dysfunction with possible serious impact on the psychological profile of both patient and partner, and most importantly, detrimental consequences on the quality of life of the couple. Premature ejaculation can have a detrimental effect on self-confidence and the relationship with the partner, and may sometimes cause mental distress, anxiety, embarrassment and depression $(3,17)$.

This data is amply confirmed by our study, which clearly shows that in a population of males affected by PE and of women partners of men affected by PE, there is a marked anxiety profile, with a significant percentage of subjects presenting a level of mild-to-moderate anxiety. On the contrary, compared to what was verified by other studies previously published, in our population of the IPER study there is no profile of a depressive state as demonstrated by the non-statistical significance of the differences in $\mathrm{PE}+$ and PE- populations of both sub-cohorts.

In our opinion, our data is reinforced by the use of a validated questionnaire such as the Z-SDS. Furthermore, our results showed a two-fold frequency of female sexual distress when the male partner is affected from PE.

It has been widely accepted that PE represents a distressing condition, not only for men who suffer from the condition but also for their female partners and that it could lead to couple breakups and lower relationship satisfaction.

In our mind, the most relevant data that emerges from this research is that, rather than talking about a male patient affected by PE it would be advisable to introduce the concept of the person affected by PE as part of a couple, because it is only through the classification of both partners and their sexual experience that the results of the treatment can be optimized. This is important, above all, in order to involve, once the diagnostic profiling phase is complete, involving both partners of the whole couple in the therapeutic process with the aim of optimizing the therapeutic outcome. Moreover, some preliminary studies have shown that a combination of dapoxetine and behavioral treatment was more effective than dapoxetine alone in patients with lifelong PE (21). There are some major limitations in the present study that must be acknowledged. Firstly, the design of the study (observational and cross-sectional) has allowed us to take a fixed picture of the condition of patients, without offering a dynamic assessment with control over time.

Secondly, PE in men (IPER-M sample) has been defined without using the ISSM evidence-based definition but only based on the presence of IELT $<1$ minute. Similarly, as regards to the female counterpart (IPER-F sample), the stratification data was based on a non-objective tool provided by the partner's self-reported IELT. 


\section{Conclusions}

Data from this large observational, non-interventional, cross-sectional, epidemiological study shows that in M-F couples involving a patient with PE there is a significant problem of sexual dissatisfaction for both partners, which is accompanied by a progressive reduction in the frequency of sexual contact as well as the onset of anxiety. Taking this into consideration, a full profile of the quality of a couple's sex life is essential to optimize the results of the PE therapy of male partner.

\section{REFERENCES}

1. Hatzimouratidis K, Giuliano F, Moncada I, et al. EAU Guidelines on Erectile Dysfunction, Premature Ejaculation, Penile Curvature and Priapism http://uroweb.org/guideline/male-sexual-dysfunction/ LAST UPDATE MARCH 2018.

2. Althof SE, McMahon CG, Waldinger MD, et al. An Update of the International Society of Sexual Medicine's Guidelines for the diagnosis and treatment of Premature Ejaculation(PE) J Sex Med. 2014; 2:60-90

3. Symonds T, Roblin D, Hart K, Althof S How does premature ejaculation impact a man's life? J Sex Marital Ther. 2003; 29:361-70.

4. Rust J, Golombok S, Collier J. Marital problems and sexual dysfunction: How are they related? Br J Psychiatry. 1988; 152:629-31.

5. Moore JT, Goldstein Y. Sexual problems among family medicine patients. J Fam Pract. 1980; 10:243-7.

6. Rowland DL, Cooper SE, Schneider M. Defining premature ejaculation for experimental and clinical investigations. Arch Sex Behav $2001 ; 30: 235-253$.

7. Limoncin E, Tomassetti M, Gravina GL, et al. Premature ejaculation results in female sexual distress: standardization and validation of a new diagnostic tool for sexual distress. J Urol. 2013; 189:1830-5.

8. Hartmann U, Schedlowski M, Kruger TH. Cognitive and partnerrelated factors in rapid ejaculation: Differences between dysfunctional and functional men. World J Urol. 2005; 23:93-101.

9. Abdo $\mathrm{CH}$. The impact of ejaculatory dysfunction upon the sufferer and his partner. Transl Androl Urol. 2016; 5:460-9.

10. Verze P, Arcaniolo D, Palmieri A, et al. Premature ejaculation among Italian men: prevalence and clinical correlates from an observational, non-Interventional, cross-sectional, epidemiological study (IPER). Sex Med. 2018; 6:193-202.

11. Verze P, Arcaniolo D, Imbimbo C, et al. General and sex profile of women with partner affected by premature ejaculation: results of a large observational, non-interventional, cross-sectional, epidemiological study (IPER-F). Andrology. 2018; 6:714-719.

12. Laumann EO, Paik A, Rosen RC. Sexual dysfunction in the United States: prevalence and predictors. JAMA, 1999; 281:537.

13. Ventus D, Jern P. Lifestyle factors and premature ejaculation: are physical exercise, alcohol consumption, and body mass index associated with premature ejaculation and comorbid erectile problems? J Sex Med. 2016. 13:1482.

14. Dunn KM, Croft PR, Hackett GI. Association of sexual problems with social, psychological, and physical problems in men and women: a cross sectional population survey. J Epidemiol Community Health. 1999; 53:144.

15. Xia Y, Li J, Shan G, et al. Relationship between premature ejac- ulation and depression: A PRISMA-compliant systematic review and meta-analysis. Medicine (Baltimore), 2016; 95:e4620.

16. Porst H, Montorsi F, Rosen RC, et al. The premature ejaculation prevalence and attitudes (PEPA) survey: prevalence, comorbidities, and professional help-seeking. Eur Urol. 2007; 51:816-23.

17. Rowland D, Perelman M, Althof S, et al. Self-reported premature ejaculation and aspects of sexual functioning and satisfaction. $J$ Sex Med. 2004; 1:225.

18. Capece M, La Rocca R, Mirone V, et al. A systematic review on ischemic priapism and immediate implantation: do we need more data? Sexual Medicine Reviews. 2019; 7:530-534.

19. Laumann EO, Nicolosi A, Glasser DB, et al. Sexual problems among women and men aged 40-80 y: prevalence and correlates identified in the Global Study of Sexual Attitudes and Behaviors. Int J Impot Res. 2005; 17:39.

20. Porst H, Montorsi F, Rosen RC, et al. The Premature Ejaculation Prevalence and Attitudes (PEPA) survey: prevalence, comorbidities, and professional help-seeking. Eur Urol. 2007; 51:816.

21. Cormio L, Massenio P, La Rocca R, et al. The combination of dapoxetine and behavioral treatment provides better results than dapoxetine alone in the management of patients with lifelong premature ejaculation. J Sex Med. 2015; 12:1609.

\section{Correspondence}

Paolo Verze, MD

pverze@gmail.com

Roberto La Rocca, MD (Corresponding Author)

robertolarocca87@gmail.com

Lorenzo Spirito, MD

lorenzospirito@msn.com

Gianluigi Califano, MD

gianl.califano2@gmail.com

Luca Venturino, MD

luca.venturino86@gmail.com

Luigi Napolitano, MD

nluigi@libero.it

Alessandro Palmieri, MD

info@alessandropalmieri.it

Vincenzo Mirone, MD

mirone@unina.it

Department of Neurosciences, Reproductive Sciences and Odontostomatology, Urology Section, University of Naples Federico II

Via S. Pansini, 580131 Naples (Italy)

Antonio Cardi, MD

acardi@hsangiovanni.roma.it

Department of Urology, San Giovanni Hospital, Rome (Italy)

Davide Arcaniolo, MD

davide.arcaniolo@gmail.com

Department of Urology, Vanvitelli University, Naples (Italy)

Claudia Rosati, MD

claudia.rosati@unina.it

Department of Clinical Medicine and Surgery, University of Naples Federico II, Naples (Italy) 